Western University Scholarship@Western

1991

\title{
Income Inequality and International Migration
}

James B. Davies

Ian Wooton

Follow this and additional works at: https://ir.lib.uwo.ca/economicsresrpt

Part of the Economics Commons

Citation of this paper:

Davies, James B., Ian Wooton. "Income Inequality and International Migration." Department of Economics Research Reports, 9111. London, ON: Department of Economics, University of Western Ontario (1991). 


\author{
RESEARCH REPORT 9111 \\ INCOME INEQUALITY AND \\ INTERNATIONAL MIGRATION \\ b.y \\ James B. Davies \\ and \\ Ian Wooton
}

September 1991

Department of Economics

Social Science Centre

University of Western Ontar1o

London. Ontar1o. Canada

N6A $5 \mathrm{C2}$

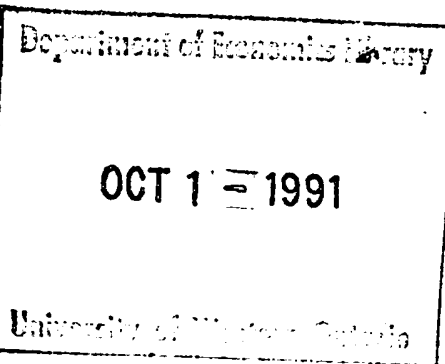




\title{
INCOME INEQUALITY AND INTERNATIONAL MIGRATION
}

\author{
James B. Davies and Ian Wooton*
}

April 1991

\begin{tabular}{ll} 
Correspondence: & \multicolumn{1}{l}{$\begin{array}{l}\text { Ian Wooton } \\
\text { Department of Economics } \\
\text { University of Western Ontario } \\
\text { LONDON, Ontario } \\
\text { Canada N6A 5C2 }\end{array}$} \\
Telephone: & $+1519661-3411$ \\
FAX: & $+1519661-3666$ \\
E-Mail: & wOOTON@UWOVAX.UWO.CA
\end{tabular}




\title{
INCOME INEQUALITY AND INTERNATIONAL MIGRATION \\ James B. Davies and Ian Wooton
}

\begin{abstract}
This paper provides a theoretical analysis of the impact of international factor movements on the personal distribution of income. It distinguishes between two types of labour (skilled and unskilled) and focusses on the consequences of their migration. There is a simple, yet powerful, relationship between factor flows, the structure of domestic production, and changes in inequality in a country. The effects of labour migration are shown to depend on whether skilled labour and unskilled labour are "friends" or "enemies" in production. We conclude with a discussion of the likely impact on inequality of some past and current migrations.
\end{abstract}

KEYWORDS: Factor migration, International trade, Inequality, Income distribution

JEL CLASSIFICATION: $410,820$. 
There has been considerable theoretical work on the consequences of international factor movements, and in particular labour migration, in both the international trade and economic development literature. [See, for example, Ramaswami (1968); Kenen (1971); Bhagwati and Rodriguez (1976); Ruffin (1981); Rivera-Batiz (1982); Gerking and Mutti (1983); Ethier (1986); Jones et al. (1986); Djajic (1987); Kuhn and Wooton (1987).] This work has focused on the welfare impact of migration, the distributive effects on factors, and policy measures. Given the large migrant flows observed in many cases, there seem to be a priori grounds for believing that distributive effects are likely very sizeable. However, despite the continuing interest in the development literature in the evolution of personal income distribution, we are not aware of any rigorous analysis of the impact of international migration on overall economic inequality, either in less developed countries (LDCs) or developed countries (DCs). ${ }^{1}$

The purpose of this paper is to provide a theoretical analysis of the impact of international factor movements on the personal distribution of income, or (equivalently) the degree of economic inequality. ${ }^{2}$ In order to get reasonably clearcut results we use a fairly simple model of trade, migration, and income distribution in which there are two traded goods and three factors. For any given country one of the traded goods corresponds to exports, and the other to imports. The three factors include capital and two types of labour: skilled and unskilled. We focus mainly on the alternative results of international migration of the two types of labour.3 Migration of skilled workers, commonly known as the "brain drain", has taken place, for example, between the Indian subcontinent and the United Kingdom and between the United Kingdom and North America. In recent years unskilled labour flows have taken place on a large scale, for example, from such countries as the Philippines and Mexico to the United States, and are anticipated to become increasingly important for the European Community as its membership expands.

There appears to be a conventional wisdom on the impact of international migration on income inequality in "source" and "host" countries, that is, the countries of emigration and immigration, respectively. Unskilled emigration is generally thought to reduce inequality in 
the source country and increase it in the host country. The brain drain, on the other hand, is viewed as doing the opposite, raising inequality in the source and lowering it in the host. We show in this paper that, while these tendencies may be present, the outcomes may differ. It is possible for the movement of unskilled labour to have an ambiguous effect on income inequality in both source and host countries. Even more strikingly, the brain drain can unambiguously reduce inequality in source countries and increase it in host countries. Which possibility is relevant for a particular source or host country turns out to depend in a simple way in our model on the relative factor intensities of imports and exports in that country.

The paper is organized as follows. Section I sets out the model. The impact of migration on income distribution in both host and source countries is examined in Section II. Section III considers some possible applications, while Section IV concludes.

\section{THE MODEL}

We consider a model in which two countries — the migrant source and host - trade with the rest of the world at exogenously determined commodity prices. Each economy produces two traded goods, under constant returns to scale, using the services of three homogeneous factors of production: unskilled labour, skilled labour, and capital, which are in fixed supply.45 Although for simplicity we do not do so, non-traded goods could be incorporated without altering the results. Initially there are barriers to free factor mobility. Then some change occurs which allows a certain amount of factor movement, although in general not enough to equalize factor earnings across nations. We shall analyze the consequences for the personal distributions of income, as represented by Lorenz curves, in the source and host countries.

As these assumptions make clear, our model is very simple, and imposes several important restrictions. It is important to bear in mind, for example, that the results will only hold rigorously for small open economies. 6 The low dimensionality in number of factors is necessary for a tractable analysis of changes in Lorenz curves; that is, for a discussion of effects on the personal distribution of income. We have chosen to consider the case of fewer 
traded goods than factors as the most interesting problem. With as many (or more) traded goods than factors, commodity prices may fully determine factor prices independently of the factor endowments. In such a case, factor migration would change the shares of income accruing to factors, but would have no effect on their earnings. In order to permit factor-price adjustments in the absence of changes in commodity prices, we must have more factors than traded goods. Despite the relative simplicity of the model, we obtain rich results that appear to have interesting real-world implications.

\section{Factor Supplies and National Income}

Unskilled labour, skilled labour, and capital are indexed by $U, S$, and $K$, respectively. ${ }^{7}$ The vector of factors employed in the host country is represented as $V=\left(V_{U}, V_{S}, V_{K}\right)$, while corresponding variables representing the source country are modified by a "*". Gross Domestic Product, $Y$, is defined as the total income generated within a country:

$$
Y=\sum_{i} w_{i} V_{i}
$$

Gross national product, $G$, is the income accruing to citizens of the country. Hence,

$$
G=Y-\sum_{i} w_{i} V_{i}^{\prime},
$$

where $V_{i}^{\prime}$ is the host-country employment of factor $i$ from the source country.

It can be shown [see, for example, Jones and Scheinkman (1977)] that, at constant commodity prices:

$$
\sum_{i} V_{i} \mathrm{~d} w_{i}=0
$$

The change in GDP is then:

$$
\mathrm{d} Y=\sum_{i} w_{i} \mathrm{~d} V_{i}
$$

while the change in GNP is:

$$
\mathrm{d} G=-\sum_{i} V_{i}^{\prime} \mathrm{d} w_{i},
$$

which is minus the change in the earnings of existing immigrant factors resulting from the influx of new immigrants. 
Suppose that our initial concern is with the distribution of income amongst citizens of the country. Immigrant workers are thought of as gastarbeiter, only temporarily resident in the host country and therefore not considered part of its income distribution, while the ownership of immigrant capital is viewed as residing abroad. The appropriate measure of income in the country is then GNP.

The first influx of foreign factors of production has no impact on GNP: with $V^{\prime}=0$, the right-hand terms of equation (5) are all zero. The increase in GDP is exactly equal to payments made to the immigrants for their services and hence the income accruing to citizens is unchanged. If there are immigrants already resident in the country, then the GNP will change. In particular, should there be further immigration of a factor, say $i$, then, as $\partial w_{i} / \partial V_{i}$ is generally negative, the earnings of the foreign factors already working in the country will be depressed (as will the earnings of the domestic factors of that type). The impact on immigrant factors of a different type, say $j$, depends on the sign of $\partial w_{j} / \partial V_{i}$; that is, their earnings will rise or fall depending on whether the incoming $i$-factors are complements or substitutes for them in production. Overall, the GNP of the country will rise if the new immigrants depress the total earnings of the resident immigrants and vice versa.

\section{Functional Distribution: "Friends" and "Enemies"}

Irrespective of whether the aggregate income of citizens changes, the immigration will influence the distribution of income amongst domestic factors. We shall adopt Ruffin's (1981) terminology by calling factors for whom $\partial w_{j} / \partial V_{i}>0$ "friends", while those for whom $\partial w_{j} / \partial V_{i}<0$ are termed "enemies". Samuelson's reciprocity relationship [see Jones and Scheinkman (1977)] indicates that: $\partial w_{i} / \partial V_{j}=\partial w_{j} / \partial V_{i}$, that is, any enmity (or friendship) is mutual. As has been noted, each factor is its own enemy, in that the return to factors of the same type as the immigrants will decline and consequently, from equation (3), the immigration must cause earnings of at least one other factor to increase. Thus every factor has at least one friend.8 In our 2-good, 3-factor case, there are two "extreme" factors and one "middle" factor, where an extreme factor is the factor used most intensively in either the import-competing 
industry or the export industry. Ruffin shows that that the extreme factors are mutual enemies, while both are friends of the middle factor.9 Kuhn and Wooton (1991) have shown that Ruffin's results are generally robust to the introduction of a non-traded good into the model, in that, although three goods are being produced, the relative intensities of the factors in the two traded industries remain the determinants of the qualitative effects on factor prices. 10 While, for simplicity, our analysis is conducted in a model without non-traded goods, it is important to recognize that their inclusion would have no qualitative impact.

We assume that any given individual holds only one type of factor. In order to discuss inequality, some assumptions must be made about the per-capita distribution of factor earnings. We shall assume that the per-capita income of a skilled worker is greater than that of an unskilled worker. ${ }^{11}$ Further, we shall assume both that capital ownership is concentrated such that capitalists have the highest incomes in the economy and that the overall per-capita income lies between the earnings of skilled and unskilled workers. Thus our assumptions state:

$$
w_{U}<\bar{w}<w_{S}<w_{K},
$$

where $\bar{w}$ is overall (or mean) per-capita income. Where necessary we shall distinguish between overall per-capita income for citizens $\left(\bar{w}_{C}\right)$ and for residents of the country $\left(\bar{w}_{R}\right)$.

Which of the three factors of production is the middle one? This can be established simply on the basis of observed factor proportions in the traded sector and is independent of elasticities of substitution in production and of the factor intensities in any non-traded sector [see Ruffin (1981)]. Three possible cases are considered. First, suppose that the two categories of labour are extreme while capital is the middle factor. This intensity ranking, in which the two types of labour are mutual enemies, will be named Case A. An inflow of either unskilled labour or skilled labour would lower both $w_{U}$ and $w_{S}$ while raising the productivity of capital, $w_{K} .12$ In contrast, Case B has unskilled labour as the middle factor and skilled labour and capital as the extreme factors, such that an inflow of unskilled workers would lower $w_{U}$ and raise both $w_{S}$ and $w_{K}$. Thus, in this case workers of different types are friends. This would also hold in Case $\mathrm{C}$, where skilled labour is the middle factor with unskilled labour and 
capital as the extremes. The three cases are summarized in Table 1. Which of these cases is appropriate for a country depends primarily on its technology. Kuhn and Wooton's (1991) results indicate that Case $A$ is relevant for the U.S. economy. This is based on the finding that U.S. exports are most intensive in $S$ while imports are most intensive in $U$. Although some other developed countries would be in this category, many, such as Japan and Germany, while having $S$-intensive exports, may be heavy importers of $K$-intensive resource-based commodities. This would put them in our Case B, where $S$ and $K$ are enemies. The oil-exporting countries, some LDCs, and DCs such as Canada and Australia are heavy exporters of primary commodities and resource-based products while being net importers of manufactures, and would also likely be in Case B.

\section{The Personal Distribution of Income}

In order to analyze the impact of factor flows on inequality we shall focus on changes induced in the Lorenz curve. This is the central analytical tool of modern inequality measurement. If the Lorenz curve moves uniformly down, then relative inequality has risen unambiguously, that is, according to any index which embodies the fundamental principle of inequality aversion. 13 Conversely, a uniform upward movement of the Lorenz curve indicates an unambiguous decline in inequality. In such comparisons the Lorenz curve lying in the superior position is said to "Lorenz dominate" the other. Below, we identify certain cases of Lorenz domination associated with factor movements. In such cases the results are very strong: much stronger than if we used a single index of inequality, say the popular Gini coefficient.

With the assumptions that have been set out above, on a residence basis we have three population subgroups in each country, within each of which there is no inequality. Thus, the corresponding Lorenz curves will be composed of three straight-line segments, with the subgroups (factors) ordered according to their per-capita income. The slope of the portion of the Lorenz curve associated with a factor $i$ equals the relative per-capita income of that factor, 
$w_{i} / \bar{w}$. Hence changes in the slope of a portion of the Lorenz curve may be due to changes in either the real income of the factor or the overall mean income of the society.

While having piecewise linear Lorenz curves makes our analysis tractable it leaves it far from trivial. On a citizenship basis the Lorenz curve will have an additional segment for each of the country's factors that are partly resident abroad, and changes in mean income become more difficult to predict. But the residence basis also generates technical difficulties. Factor movements lead to changes in population proportions for the $U, S$, and $K$ groups, so that changes in the slopes of the three segments of the Lorenz curve change do not fully identify Lorenz curve movements. These subtleties explain why the impacts of factor movements on inequality are not obvious. They also likely account for the lack of previous formal modelling in this area.

\section{THE IMPACT OF INTERNATIONAL MIGRATION}

We discuss in turn the effects of immigration on income inequality among citizens and residents (that is, the factors whose services are employed in a country) for both the host and source countries. The results for citizens are of considerable interest for countries which treat their immigrants as gastarbeiter, or which have substantial illegal immigration. However, for many countries, whose immigrants are expected eventually to become citizens, the distribution among residents may be of greater interest. We establish, below, the consequences of migration for each nation's inequality under the various assumptions about technology.

The impact of migration on income distribution depends on two features of our analysis. First, the immigration will depress the earnings of at least one factor group (the migrant factor's return must fall) while raising the real income of at least one other factor in the host country. Equally, factor rewards are perturbed in the source country. Second, when there is an existing immigrant population, the overall per-capita income of the population group under consideration (citizens or residents) will change as a result of the further factor movements. 
We confine our discussion, for the sake of simplicity, to cases where only one type of factor migrates and we can establish what happens to the mean income irrespective of the technological assumptions. (The net effect of multiple factor movements, such as involved in entrepreneurial migration, can be examined by applying our analysis to a sequence of separate factor movements.) On a citizenship basis, if there are any existing migrants, immigration raises $\bar{w}$ in the host country. The first immigrant is paid his/her value marginal product. Subsequent migrants, while being paid their marginal products, depress the earnings of existing migrants, thereby raising the average earnings of the host population. For the source country's citizens, migrating factors earn higher foreign returns at the sacrifice of their domestic value marginal product. Further migration has the externality of lowering the earnings of other migrants such that eventually overall per-capita income $\left(\bar{w}^{*}\right)$ would decline with continued departures of workers. 14 We assume that emigration is less than free, such that $\bar{w}^{*}$ still rises as factors exit domestic production. This is ensured for emigration of factor $j$ if $\left(w_{j}-w_{j}^{*}\right)>-V_{j}^{\prime} \partial w_{j} / \partial V_{j}^{\prime}$. On a residence basis our concern is whether the migrant factor's return is greater or less than the average in the country. In our ranking (6), we have assumed that an inflow of unskilled labour into the host country will lower $\bar{w}$, while immigration of skilled labour or of capital (and its owners) will raise average earnings. In the source country the reverse is true: $\bar{w}^{*}$ rises with the emigration of the poorest factor and declines as skilled labour and capital exit.

The following is an examination of the effects of factor migration for selected cases, our focus being on labour migration; the detailed derivations for the other cases are left to the interested reader. The complete results are listed in Table 2 . In some cases, the returns to two of the three factors move in the same direction as the mean income, raising the possibility that, for one of the two similarly-affected factors, the relative change is in the opposite direction, resulting in intersections in the Lorenz curve when previously there were none (or vice versa). An entry being marked " $\uparrow$ " indicates that, on a citizenship basis, the result shown becomes ambiguous when there are existing migrants, due to impact of the factor movements on overall 
per-capita income. Entries marked " $₫$ " are ambiguous on a residence basis. We show in an appendix (available on request) that relatively mild restrictions on general-equilibrium demand elasticities can be provided that eliminate these latter ambiguities. On the basis of such restrictions, we have listed the "leading cases" for the effects of the migration flows.

\section{(a) Distribution in the Host Country}

CASE A ( $U$ and $S$ enemies)

Figure 1 illustrates the change in the Lorenz curve for citizens that must occur given the initial influx of immigrants, whether skilled or unskilled, under the assumption that all workers are enemies. As has been determined above, GNP remains unchanged, but is redistributed among the factors. Capital, the factor earning the highest per-capita income, experiences an increase in its return, while the two less well-paid factors earn smaller returns. The Lorenz curve shifts down uniformly, indicating an unambiguous increase in inequality among citizens of the host country.

Were the immigration to continue, the country's GNP would increase as $w_{U}$ and $w_{S}$ were pushed down further, reducing the earnings of existing immigrant workers. In such a case, as the mean income of citizens $\bar{w}_{C}$ rises the share of income accruing to the owners of capital would further increase, leading to greater inequality in income among citizens. This result will also hold for skilled labour's immigration when our focus is on residents of the country as the skilled workers raise the average income. Migration of unskilled workers lowers $\bar{w}_{R}$, raising the possibility that $w_{U} / \bar{w}_{R}$ might rise, resulting in an intersection of the Lorenz curves. Fortunately, it is not difficult to show that $w_{U} / \bar{w}_{R}$ declining is the leading case. 15

CASE B ( $S$ and $K$ enemies)

Immigration of the middle factor, unskilled labour, depresses that factor's earnings while increasing the returns to the other (better-paid) factors. The Lorenz curve for citizens shifts down, unambiguously, as shown in Figure 2, reflecting increased inequality. Further inflows, by diminishing existing immigrants' earnings, may further increase the inequality by raising the 
shares of the top two income groups. However, were the increase in the return to capital $w_{K}$ proportionately less than the increase in the average return to citizens $\bar{w}_{C}$, then the upper part of the Lorenz curve would become flatter resulting in an intersection of the old and new Lorenz curves. Again, this ambiguity could be avoided by placing relatively weak restrictions on general-equilibrium demand elasticities, as illustrated for Case $A$ in the appendix. On the other hand, the inflow of unskilled labour lowers $\bar{w}_{R}$ ensuring that inequality will continue to increase on the residence basis.

Immigration of skilled workers raises unskilled earnings while pushing down $w_{S}$ and $w_{K}$. Inequality necessarily declines as the Lorenz curve shifts up and the share of GDP accruing to the unskilled workers rises. As unskilled labour is the only factor group whose income increases, the increase in $w_{U}$ must be proportionately greater than that of both $\bar{w}_{C}$ and $\bar{w}_{R}$, guaranteeing a continuing decline in inequality as migration continues on both a citizenship and residence basis.

CASE C ( $U$ and $K$ enemies)

Immigration of any factor of production causes the slopes of the tails of the Lorenz curve to move in the same direction (becoming flatter for immigration of unskilled workers and capital inflows, and steeper for skilled immigration). This is illustrated in Figure 3. This guarantees an intersection in the Lorenz curve and the consequent ambiguity about the impact on inequality.16 The intersection ambiguity may be resolved by further factor inflows. For example, immigration of skilled labour raises the earnings of unskilled labour and capital as well as increasing overall per-capita income (both for residents and citizens). If the increase in the average income were proportionately greater than that of $w_{U}$ then unskilled labour's share of GDP would be declining together with skilled labour's share and inequality would unambiguously rise. Were the share of capital to decline instead, the ambiguity would again be resolved as inequality fell as a result of the continued immigration. 


\section{(b) Distribution in the Source Country}

The analysis for the source country is in many respects merely a mirror image of that for the host. Indeed, the results using the residence basis are exactly the reverse: such that, emigration's impact on inequality is the opposite to that of immigration for a similar (that is, having the same technology) nation.

A complication arises when we use the citizenship criterion in that the emigrant factor will earn more than his compatriot who remains in the source country. Thus one segment of the Lorenz curve will fracture into two. This does not affect the results as long as we can assume that, while the foreign return to a factor is larger than that at home, the difference is not so great that emigrant unskilled workers earn more than domestic skilled workers and that emigrant skilled workers earn more than the owners of domestic capital.

Given this, the impact of emigration on inequality is generally in the same direction on both residence and citizenship bases, the differences for continued migration flows being due to $\bar{w}_{C}$ rising for all forms of factor emigration whereas $\bar{w}_{R}$ only rises when unskilled workers leave.

\section{APPLICATIONS}

One response to the question as to the impact migration has on income distribution is that "it's obvious". If, for example, unskilled workers migrate from Mexico to the United States, it may seem self-evident that inequality will decline in Mexico and increase in the United States. A major contribution of this paper is to show that matters are more complex. If, for example, both Mexico and the United States fell into our Case C, where unskilled labour and capital are enemies, then this kind of migration would most likely lead to ambiguous movements of the Lorenz curves in both countries.

While ambiguities are possible, our analysis has also shown that they are not pervasive. In two of the three factor-intensity cases considered (A and B), under mild conditions we do find that unskilled migration will unambiguously reduce inequality in the source country and 
increase it in the host country. Flows of capital from a poorer to a richer country in these two cases will do just the opposite. Migration of skilled workers reduces inequality in the source country and raises it in the host country (like unskilled migration) if unskilled and skilled labour are enemies (that is, in Case A) which we have some evidence to believe is relevant for the United States. On the other hand, if the two kinds of labour are friends, and skilled labour is an enemy of capital (case B), which we argued is plausible for many source and host countries, this "brain drain" increases inequality in the source country and reduces it in the host country. Finally, entrepreneurial migration, which can be thought of as combining movements of skilled labour and capital, will have ambiguous effects for Case A countries, but will increase inequality in a Case B source and reduce it in a host country of type B.

In principle these predictions are testable. At a minimum, for either a source or host country involved in an important migration, time-series data would be required on: (i) factorintensities of imports and exports, (ii) inequality of factor income, (iii) migrant flows, and (iv) other important determinants of inequality such as demographics, structure of labour demand, and unemployment rates. Better results could be achieved with combined timeseries/cross-section data; for example, making use of the annual CPS data in the U.S. Such exercises are beyond the scope of the present paper. Here we first discuss the directions of likely distributional effects for some important migrations on the basis of our model. We then ask how these predictions fare when confronted by existing empirical evidence.

As mentioned above, Kuhn and Wooton (1991) find that exports and imports in the United States are intensive in $S$ and $U$, respectively, putting it in our Case A. An important feature of this case is that all immigration (except entrepreneurial) is predicted to increase inequality. ${ }^{17}$ While some other DCs no doubt also fall in Case A, the majority likely fall into our Case B. As mentioned above, for countries like Japan and Germany resource-based commodity imports (that are likely $K$-intensive) are relatively much more important than for the U.S. Such countries may thus have $K$-intensive imports and $S$-intensive exports (i.e., mostly manufactures), putting them in our Case B where $S$ and $K$ are enemies. The resource- 
poor newly industrializing countries (NICs), like Taiwan, Singapore, Hong Kong, and South Korea, likely fall in Case B for the same reason, although the poorer members of this group (like many LDCs) may have $U$-intensive exports and therefore fall in Case C. A few industrial countries, such as Canada and Australia, and the oil-exporting countries, are likely also in Case B because they are important primary and resource-based exporters and import a large volume of manufactures. 18

We thus conjecture that, except for the U.S. and a few others, most developed and oil-exporting countries, which make up a large portion of recent host countries, likely fall in our Case B. This would mean that for many host countries, the arrival of unskilled workers has tended to increase inequality, while the brain drain and entrepreneurial immigration have likely decreased it. It is difficult to generalize about the numerous source countries, since they are likely scattered across Cases A, B, and C.

The United Kingdom is of particular interest, due to a significant change of regime occurring in the 1970s. In the 1950-60s the U.K. was, roughly speaking, a resource-poor manufacturing exporter experiencing net emigration of skilled workers and considerable unskilled immigration, largely from "New Commonwealth" countries. In the 1970-80s approximate self-sufficiency in the capital-intensive energy sector was achieved, altering greatly the factor intensity of imports. 19 At the same time, unskilled immigration largely came to a close and freer mobility of labour within Europe began. Net emigration of skilled workers continued.

The U.K. of the 1950-60s likely fell in our Case B, while the resource-rich U.K. of the 1970-80s may be of the Case A type. If so, the unskilled immigration of the 1950-60s would have increased inequality, and this would have been exacerbated by the loss of skilled labour.20 In contrast, the continued loss of skilled workers under the new regime of the 1970-80s should have acted in the reverse, putting a brake on rising inequality.

What empirical evidence is there of the effects of migration on inequality? There are two types. First, we have a fairly large number of studies which confirm either that when a 
factor migrates its rewards increase in the source country or that they decline in the host country. 21 This is important evidence, even though it may not seem surprising, since as the work by Gerking and Mutti (1983) shows, other outcomes are possible in alternative models. The second kind of evidence concerns gross correlations between major migrations and changes in income inequality. Such evidence has obvious limitations. However, we believe it is worth examining as a first step in evaluating our model.

One difficulty in checking predictions is that while the model looks at the distribution of factor income among individuals, most real-world data is either for the distribution of total income (including transfer payments) among families or (less often) individuals, or for the distribution of labour earnings among individuals. None of this data is ideal for our purposes, but, equally, none of it should be ignored. Our approach has been to try to make use of all the available evidence, noting carefully the income concept or family unit being used. 22

Turning to the evidence, consider first the effects of the mainly unskilled migration of workers from LDCs to the U.S. in the last several decades. Although Friedlander (1965) did not study income distribution changes explicitly, the data he presents on the size and composition of the mainly unskilled emigration from Puerto Rico to the U.S. in the 1950s, as well as on the decline of Puerto Rican skill differentials in wages and growth of real earnings, strongly suggest that inequality declined in Puerto Rico as a result of this emigration.23 Similarly, from the 1960 s to the mid-1980s there was a substantial decline in income inequality among families in Mexico, which sent approximately 2.5 million emigrants, or about $4 \%$ of its population, to the United States over the period 1970-1980 alone.24 On the receiving side, during the period of heaviest immigration, since the mid 1970s, both income and earnings inequality have shown a steady upward trend in the United States. ${ }^{25}$ Although there is considerable interest in the U.S. in explaining this trend, it is so far imperfectly understood. While many factors seem to be at work, several authors have drawn attention to the possible contribution of immigration. (See, e.g., Greenwood and McDowell, 1986; Borjas, 1987; and Bound and Johnson, 1989.) 
Another important example is provided by the 19th and early 20th century migration from the "Old World" to the "New", which was primarily unskilled. (See, e.g., Thomas, 1973.) As detailed by Williamson and Lindert (1980), income inequality among individuals increased in the United States over the entire period of heavy immigration from 1820 until 1914 (p. 95), but it appears to have decreased significantly in the United Kingdom.26 This would be expected, provided that neither source nor host countries were of type C.

While we believe that most important migrations have likely had significant effects on income inequality in source or host countries, there are no doubt exceptions. Some migrations, although large in absolute terms, have been small in relative terms in the source or host countries. Thus, for example, the emigration of unskilled workers from India or China, that began in the first half of the 19th century, may have had little impact on overall inequality in the source countries. 27 Conversely, while the wholesale emigration of unskilled workers from Ireland almost certainly had a major effect on income inequality in that country 28 , the impact on inequality in a much more populous destination country, such as the U.S., may have been relatively small. And, in countries experiencing long-standing migrations, such as LDCs experiencing "brain drain", domestic patterns of human-capital investment may largely adjust to offset the impact on relative populations of skilled and unskilled workers (see, e.g., Reubens, 1987, pp. 25-26).

Finally, there are some cases where our model casts doubt on the "evidence", rather than the other way around. For example, consider some of the views about the impact of entrepreneurial immigration in the Third World. Bauer (1972 pp. 459-461), for example, discussed the impact of commercial immigrants from such countries as India and Lebanon in East and West Africa, respectively. While arguing that the immigrants made an important contribution to economic development, Bauer suggests that, by rapidly swelling the ranks of successful entrepreneurs, their arrival led to a conspicuous increase in income inequality. There are, in fact, no relevant distribution estimates. It may be that resentment against the newcomers fostered a belief that inequality had risen, whereas it actually fell (if the host 
countries were in our Case B) or changed in an ambiguous fashion. There is no case in our model where one can say with assurance that a combined inflow of skilled labour and capital would definitely increase overall inequality.

\section{Iv. CONCLUSION}

This paper has studied a neglected aspect of the theory of international factor migration, that of its consequences for the personal distribution of income. We have presented a simple, yet powerful, relationship between factor flows, the structure of domestic production, and changes in inequality in a country.

We have shown that out of three possible cases, in the two which are empirically most relevant, at least for host countries, unambiguous results are obtained. Knowledge of relative factor intensities in traded goods production is sufficient to determine, under relatively weak restrictions on general-equilibrium factor-demand elasticities, the qualitative effects on inequality of either immigration or emigration of a factor of production. What is central to the effects of labour migration is whether skilled and unskilled labour are friends or enemies in production. In the former case, any labour immigration generally increases, and emigration decreases, inequality. In the latter case, an outflow of skilled labour will harm unskilled workers, increasing inequality, and an inflow of skilled labour will do the reverse.

The predictive content of our theory could be tested formally using time-series data on factor intensities, migratory flows, and income inequality for countries experiencing significant migrations. Such an investigation is beyond the scope of the present paper, but remains an important avenue for future research. Here we have limited ourselves to noting the confirmation in the empirical literature of the predicted impact of immigration on wage rates, and to a discussion of the directions of impact for a range of past and current migrations which appear to be predicted by the model. In a number of cases we have been able to show that the gross correlations between migration and changes in inequality are strikingly consistent with our predictions. 


\section{NOTES}

*University of Western Ontario, London, Canada N6A 5C2. Wooton acknowledges financial support from the Sloan Foundation and the Social Sciences and Humanities Research Council of Canada. This is the revised version presented at the annual meetings of the Canadian Economic Association, Québec City, June 1989. We are grateful for comments from an associate editor and two anonymous referees of this JOURNAL, and those of participants in seminars at the Norges Handelshøyskole, the ESRC/International Economics Study Group, and Universities of Edinburgh, Geneva, and Glasgow.

1Many authors have discussed some of the implications of their theoretical work for personal income distribution. (See, e.g., Johnson, 1980, or Gerking and Mutti, 1983.) However, these discussions are limited to changes in factor rewards and ignore the complications posed by changes in the number of owners of different factors. Also, the need to distinguish between impacts for citizens versus residents has not been pointed out. Our analysis handles these difficulties explicitly.

In this paper we confine our attention to the behaviour of relative inequality, that is to the income distribution standardized by its mean. Recently, there has been interest in the "generalized Lorenz curve" of Shorrocks (1983) which does not standardize by the mean, and therefore responds to changes in aggregate income as well as distribution. It is straightforward to extend the present results to analyze movements in generalized Lorenz curves. For the sake of avoiding too tedious a taxonomy, and in view of the fact that the results become generally more ambiguous, we do not present them here.

3While our model can be used to analyze the consequences of international capital movements as well as labour migration this is fraught with hazards. For example, as the location of capital in the real-world can be distinct from the country of residence or citizenship of its owner, the implications of changes in the capital stock for income inequality in a country will depend on whether the owner of the capital has moved as well. 
${ }^{4}$ We follow the literature in considering only the case of constant returns to scale in production. While a comprehensive discussion of increasing returns to scale is beyond the scope of this paper, it should be noted that their presence would provide additional aggregate benefits to the host country from factor inflows, but that their consequences for the distribution of income would depend on the specific formulation of the production functions.

In principle it would be desirable to incorporate endogenous factor supply. However, if factor supplies are endogenous we cannot make clearcut predictions without a considerable loss of generality. Johnson (1980) analyzes the impact of factor movements for a host country, with the same three factors as in our model, but allowing endogenous domestic supply of the migrating factor. However, in order to get results on income distribution Johnson assumes an aggregate CES production function, which is highly restrictive relative to the production structure in our model. In our opinion it is not worth accepting such a loss of generality, especially since empirical studies indicate that labour supply is fairly inelastic. (Johnson's own preferred estimate of the reduction in number of domestic unskilled workers on the immigration of a single unskilled worker is 0.1.)

${ }^{6}$ Gerking and Mutti (1983) consider a two-country model with the same three factors considered here. As mentioned later, their results are very interesting, and differ from ours in a striking way. Thus, in thinking about applications it may be important to consider whether small or large economy analysis is more relevant.

7By "capital" we mean non-human primary inputs into the production process.

${ }^{8}$ For a more complete discussion of this, see Ruffin (1981) or Jones and Easton (1983).

${ }^{9}$ As noted earlier, Gerking and Mutti (1983) consider a two-country model with the same three factors considered here. One of the countries is thought of as developed, the other as less developed. The developed country has all three factors and produces two goods, whereas the LDC is missing skilled labour, and produces only one good. In this framework the impact of 
migration of unskilled workers on all wage rates is in the same direction; the effect on the return to capital is in the opposite direction to that on wages; and wage rates may rise or fall as a result of the migration. Thus, the Gerking and Mutti case differs from that considered here in that unskilled labour (i) may be its own friend, and (ii) is an enemy to skilled labour if and only if it is its own enemy. As noted earlier, these differences from our results are sufficiently striking that, in any application, one ought to think carefully about whether a small or large economy analysis is the more appropriate.

10The conditions are the normality of demand for traded goods and a restriction on relative factor intensities in non-traded good production [satisfied in Kuhn and Wooton's (1991) data].

${ }^{11}$ Were all human factors identical, then in an intertemporal model with endogenous skills the present value of lifetime earnings of skilled workers, taking account of earnings foregone during training and the costs of education, would be the same as that of unskilled workers in equilibrium. We therefore have in mind that there are different aptitudes within the labour force driving some to choose to acquire skills while others remain unskilled. However, we ignore differences in abilities within a skill group.

12The intuition is as follows. $U$ and $S$ are "extreme" because import-competing goods are relatively most intensive in one of these factors and export goods in the other. Suppose exports are intensive in $S$. Then an inflow of skilled workers, for example, depresses $w_{S}$. At constant commodity prices the returns of either $U$ and $K$ will rise. Both cannot rise otherwise the factor cost of producing the import good (which hires relatively few skilled workers) would be driven above its price. A rise in $w_{U}$ that was sufficiently large to yield zero profits in the export industry would drive production costs of the import-competing good above its price. Equilibrium can only be restored by a rise in the return to the middle factor, balanced by falls in each industry's most intensively used and least intensively used factors. That is the returns to both extreme factors must fall while those of the middle factor must rise.

13Inequality aversion is synonymous with the famous Pigou-Dalton "principle of transfers". [See, 
for example, Shorrocks and Foster (1987).] This says that if we take from a richer individual to give to a poorer, inequality must be regarded as declining (and the converse). For a discussion of the central importance of the Lorenz curve, and its relation to the wide variety of possible indexes of inequality, see Sen (1973).

14Free emigration is therefore not the optimal migration policy for the source country. The classic discussion of migration policy is Ramaswami (1968).

15A sufficient condition for an unambiguous downward movement of the Lorenz curve to go through in the face of declining $\bar{w}_{R}$ is that both $w_{U} / \bar{w}_{R}$ and $w_{S} / \bar{w}_{R}$ should decline. This will occur if and only if the general equilibrium demand elasticities for $U$ and $S$ with respect to $w_{U}, \varepsilon_{w_{U}}^{U}$ and $\varepsilon_{w_{U}}^{S}$ satisfy:

$$
\varepsilon_{w_{U}}^{U}, \varepsilon_{w_{U}}^{S}>-\frac{1}{D}
$$

where $D$ is the proportional "income deficit of the unskilled": $D \equiv\left(\bar{w}_{R}-w_{U}\right) U / Y$. (See Proposition 1 in the appendix.) Based on U.S. data, if the $U$ group comprises between $20 \%$ and $40 \%$ of the population $D$ would lie somewhere between about 0.15 and 0.25 . Thus demand elasticities less than about 4 in absolute value would let our results go through.

${ }^{16}$ When Lorenz curves intersect there is a fundamental ambiguity in inequality rankings. All we can say here is that some of those who subscribe to what Shorrocks and Foster (1987) have labelled "transfer sensitivity" would regard $U$ or $K$ inflows as increasing inequality (due to the worsening of the distribution at the bottom), whereas all those showing transfer sensitivity would feel that $S$ immigration reduced inequality if the worsening at the top were sufficiently "small". As pointed out by a referee, one's understanding of the essential ambiguity can be enhanced by thinking in terms of the "relative mean income" curves before and after migration. Such curves plot incomes relative to the mean, that is the derivative of the Lorenz curve. Their changes in shape can readily be deduced from Table 1 .

${ }^{17} \mathrm{An}$ interesting exception is the case of entrepreneurial immigration. Since capital inflows tend 
to reduce inequality in Case $\mathrm{A}$, the arrival of entrepreneurs, bringing both skilled labour and capital, has an ambiguous effect on inequality.

18The Canadian case is interesting since, while the Canadian and U.S. economies have much in common, they exhibit recent divergences with respect to both immigration and inequality. Canada has not experienced the flood of illegal (mostly unskilled) immigration that has occurred in the U.S. Although the quality of legal migrants (who are more skilled) is similar for the two countries, this therefore means that Canada has attracted relatively more skilled immigrants than the U.S. If Canada is a Case B country, then it should not have experienced as much of an upward trend in income inequality as the U.S. (Also note that entrepreneurial immigration, which has been encouraged in Canada, depresses inequality for a Case B country.) Whether we look at families or male individuals, income inequality in Canada has exhibited little trend over the period since 1975, in contrast to the U.S. [See Wolfson, 1986, and McWatters and Beach (1989) ]. We do not believe that this can be accounted for entirely by such influences as diverging income-maintenance policies in the two countries.

${ }^{19}$ Data for 1987 show that the U.K.'s net exports of fuels were valued in excess of \$US 4 billion. 20The early and mid 1950s saw net (total) emigration from the U.K., while the late 1950s and early to mid 1960s were a period of overall net immigration and the largest inflow of relatively unskilled workers. While, as in all of the examples we provide in this section, migration was but one of the many forces at work, it is interesting to note that, consistent with our predictions about the effect of unskilled immigration, the shares of bottom income groups declined in the U.K. from 1954 to 1964, according to the "Blue Book" data on the distributin of income before tax among tax (i.e. family) units. The share of the bottom 30\%, for example, declined from $10.3 \%$ in 1954 to $9.7 \%$ in 1959 and to $9.5 \%$ in 1964, but thereafter increased. [See Royal Commission (1980) Table 6.1, p. 72.] The shares of top income groups (before tax) declined throughout the postwar period up to the mid 1970s.

21 In an early study, Friedlander (1965, p. 91) estimated that the Puerto Rican labour force would 
have been about $50 \%$ larger in 1960 in the absence of emigration to the U.S. in the preceding years. The emigration was heavily of unskilled, especially farm, workers. Evidently as a result, between 1952 and 1962 Puerto Rican wage differentials across skill categories fell dramatically (Friedlander, 1965, table 5.5, p. 123). Greenwood and McDowell (1986, pp. 1753-1757) survey the more formal recent literature which establishes the depressing effects of immigration on wages both in particular regions and industries, and in the U.S. as a whole. At the aggregative level, Grossman (1982) and Borjas (1987), using quite different methods, find that immigration has a small but significant effect on natives' wages, and a strong negative effect on the wages of foreign born workers living in the U.S.

22Family unit data cannot be rejected out of hand, since they are more widely available than individual data, and since the latter present problems of their own. (Both kinds of data omit the value of home production, and therefore are contaminated by shifts in labour supply between the household and market sectors. Family unit data may be less seriously affected since the split in total labour supply by family members between home and the labour market is more stable than that for individual workers.) The principal drawbacks with family unit data are that family composition may be changing over time (e.g. more single parent families), and that ownership is more likely to be dispersed across factor types for a family than for an individual. Finally, while inequality in family and individual distributions shows far from a perfect correlation, in those countries where both kinds of data are available, such as Canada and the United States, trends over time are similar for families and male individuals. See, e.g., the detailed tables in McWatters and Beach (1989).

${ }^{23} \mathrm{~A}$ necessary qualification is that Friedlander also drew attention to the rapid growth of investment and capital income in Puerto Rico over this period. Thus, to establish firmly that inequality declined one would need explicit income distribution data.

24Over the period 1970-80 according to the U.S. Census 1,270,000 immigrants entered the U.S. from Mexico. It appears that about an equal number were likely not enumerated by the 1980 
Census. [See Greenwood and McDowell (1986) pp. 1739-40 and especially their footnote 1.] The immigrant Mexican workers were largely unskilled.

The share of total income received by the bottom $40 \%$ of families in Mexico rose from a 1960 s level of about $8 \%$ to more than $10 \%$ in 1977 (see Altimir, 1987, Table 5, p. 154). From 1968 to 1977 the share of the top $10 \%$ fell from about $48 \%$ to just $40 \%$ and the Gini coefficient declined from 0.606 to 0.518 . (Independent data indicate that there was a substantial reduction in earnings inequality over the period 1960-75. See Gregory, 1986, p. 260) More recent data are on a quarterly, rather than annual basis, and are available from the 4th quarter of 1983 to the 4th quarter of 1984, and for the 3rd quarter of 1989. (An unpublished summary of these data is available from the authors on request. The most recent published data are in Instituto Nacional de Estadistica, 1989.) The reduction in inequality continued through the fourth quarter of 1984, at which point the Gini coefficient stood at 0.454. The 1989 data indicate an increase in inequality, to a level slightly below that in 1977.

25Between 1975 and 1988 the Gini coefficient for the CPS household distribution of income before-tax in the U.S. rose from 0.397 to 0.431 ; the share of the bottom quintile fell from $4.3 \%$ to $3.8 \%$; and the share of the top quintile increased from $43.6 \%$ to $46.8 \%$ (U.S. Bureau of the Census, 1990, table 6, p. 30). Controlling for sex, the distribution of both earnings and total income among male individuals showed a similar trend. See, e.g., Blackburn and Bloom (1987, pp. 590-594).

26While emphasizing that some judgement is required, Soltow (1980, pp. 66 and 67) summarizes the U.K. evidence, which is also for individuals, as indicating little change, or possibly a slight decline, between 1801 on the one hand and 1867 and 1880 on the other. Inequality in 1911 and 1913, however, appears to have been significantly less than in 1867 and 1880.

${ }^{27}$ According to Madhavan (1987, p. 88), as of 1981 the overseas population of Indian origin amounted to between 13 and 14 million, and the Chinese to between 15 and 20 million. While these are large numbers, they are of course small in relation to the populations in the source 
countries.

${ }^{28}$ We are not aware of relevant estimates of income distribution for Ireland. However, the emigration figures are very striking. In 1851 the population of Ireland was $6,552,000$. Over the next 50 years there were $3,846,000$ emigrants, resulting in a reduction in population to 4,457,000 [Thomas (1973), Table 15, p. 74]. 


\section{REFERENCES}

Altimir, Oscar (1987). "Income distribution statistics in Latin America and their reliability." Review of Income and Wealth, vol. 33 (2), pp. 11-56.

Atkinson, A.B. (1983). The Economics of Inequality, 2nd Edition. Oxford: Clarendon Press. (1987). "On the measurement of poverty". Econometrica, vol. 55, pp. 749-64.

Bauer, P.T. (1972). Dissent on Development. Cambridge, Mass.: Harvard University Press. Bhagwati, Jagdish N. and Rodriguez, Carlos (1976). "Welfare-theoretical analyses of the brain drain". In The Brain Drain and Taxation: Theory and Empirical Analysis (ed. J.N. Bhagwati). Amsterdam: North-Holland, pp. 85-111.

Blackburn, McKinley L. and Bloom, David E. (1987). "Earnings and income inequality in the United States". Population and Development Review, vol. 13, pp. 575-609.

Borjas, George (1987). "Immigrants, minorities, and labor market competition". Industrial and Labor Relations Review, vol. 40, pp. 382-392.

Bound, John and Johnson, George (1989). "Changes in the structure of wages during the 1980's: an evaluation of alternative explanations". National Bureau of Economic Research Working Paper Series No. 2983.

Djajic, Slobodan (1987). "Illegal aliens, unemployment and immigration policy". Journal of Development Economics, vol. 25, pp. 235-250.

Ethier, Wilfred J. (1984). "Higher dimensional issues in trade theory". In Handbook of International Economics, Vol. 1. (ed. R.W. Jones and P.B. Kenen). Amsterdam: North-Holland, pp. 131-184.

(1986). "Illegal immigration". American Economic Review, vol. 76, pp. 56-71.

Friedlander, Stanley L. (1965). Labor Migration and Economic Growth, A Case Study of Puerto Rico. Cambridge, Mass: MIT Press.

Gerking, Shelby D., and John H. Mutti (1983). "Factor rewards and the international migration of unskilled labor: a model with capital mobility". Journal of International Economics, vol. 14, pp. 367-380. 
Greenwood, Michael J. and McDowell, John M. (1986). "The factor market consequences of U.S. immigration". Journal of Economic Literature, vol. 24, pp. 1738-72.

Gregory, Peter (1986). The Myth of Market Failure, Employment and the Labor Market in Mexico. Baltimore: Johns Hopkins University Press for the World Bank.

Grossman, Jean B. (1982). "The Substitutability of natives and immigrants in production", Review of Economics and Statistics, vol. 54, pp. 596-603.

Instituto Nacional de Estadistica (1989). Encuesta Nacional de Ingresos y Gastos de los Hogares, Tercer Trimestre de 1984. Government of Mexico.

Johnson, George E. (1980). "The labor market effects of immigration". Industrial and Labor Relations Review, vol. 33, pp. 331-341.

Jones, Ronald W. and Scheinkman, Jose A. (1977). "The relevance of the two-sector production model in trade theory". Journal of Political Economy, vol. 85, pp. 909-936. and Easton, Stephen T. (1983). "Factor intensities and factor substitution in general equilibrium". Journal of International Economics, vol. 15, pp. 65-99.

, Coelho, Isaias, and Easton, Stephen T. (1986). "The theory of international factor flows: the basic model". Journal of International Economics, vol. 20, pp. 313-328.

Kenen, Peter B. (1971). "Migration, the terms of trade and economic welfare in the source country". In Trade, Balance of Payments and Growth (ed. J.N. Bhagwati et al). Amsterdam: North-Holland, pp. 238-260.

Kuhn, Peter J. and Wooton, Ian (1991). "Immigration, international trade, and the wages of native workers". In Trade, Immigration, and Welfare (ed. R. Freeman and J. Abowd). Chicago: University of Chicago Press for the NBER.

LaLonde, Robert and Topel, Robert (1991), "Immigration and wages". In Trade, Immigration, and Welfare (ed. R. Freeman and J. Abowd). Chicago: University of Chicago Press for the NBER. 
Madhavan, M.C. (1987). "Indian emigration: its dimension and impact on the Indian economy". In The Economics of Mass Migration in the Twentieth Century (ed. Sidney Klein). New York: Paragon House.

McWatters, Catherine G., and Beach, Charles M. (1989). "The changes behind Canada's income redistribution: cause for concern?" Queen's Papers in Industrial Relations, 1989-1, School of Industrial Relations, Queen's University, Kingston, Ontario.

Ramaswami, V.K. (1968). "International factor movement and the national advantage". Economica, vol. 35, pp. 309-310.

Reubens, Edwin P. (1987). "Benefits and costs of migration". In The Economics of Mass Migration in the Twentieth Century (ed. Sidney Klein). New York: Paragon House.

Rivera-Batiz, Francisco L. (1982). "International migration, non-traded goods and economic welfare in the source country". Journal of Development Economics, vol. 11, pp. 81-90.

Royal Commission on the Distribution of Income and Wealth (1980). "The distribution of income in the United Kingdom". In Wealth, Income, and Inequality (ed. A.B. Atkinson). Oxford: Oxford University Press.

Ruffin, Roy J. (1987). "Trade and factor movements with three factors and two goods". Economics Letters, vol. 7, pp. 177-182.

Sen, Amartya (1973). On Economic Inequality. Oxford: Clarendon Press.

Shorrocks, Anthony F. (1983). "Ranking income distributions". Economica, vol. 50, pp. 3-17.

and Foster, James (1987). "Transfer sensitive inequality measures". Review of Economic Studies, vol. 54, pp. 485-497.

Soltow, Lee (1980). "Long-run changes in British income inequality". In Wealth, Income, and Inequality (ed. A.B. Atkinson). Oxford: Oxford University Press.

Thomas, Brinley (1973). Migration and Economic Growth, A Study of Great Britain and the Atlantic Economy, 2nd Edition. Cambridge: Cambridge University Press. 
U.S. Bureau of the Census (1986), Money Income and Poverty Status of Families and Persons in the United States: 1985. Current Population Report Series P-60, Washington, D.C.

Williamson, Jeffrey G. and Lindert, Peter H. (1980). American Inequality, A Macroeconomic History. New York: Academic Press.

Wolfson, Michael (1986). "Stasis amid change - income inequality in Canada 1965-1983". Review of Income and Wealth, series 32, pp. 337-370. 
Table 1

Effects on factor earnings as a result of factor immigration

\begin{tabular}{|c|c|c|c|c|}
\hline & & \multicolumn{3}{|c|}{ FACTOR EARNINGS } \\
\hline \multicolumn{2}{|c|}{ FACTOR FLOWS } & $\begin{array}{c}\text { Unskilled } \\
\text { Labour } \\
w_{U}\end{array}$ & $\begin{array}{c}\text { Skilled } \\
\text { Labour } \\
w_{S}\end{array}$ & $\begin{array}{c}\text { Capital } \\
\text { Owners } \\
w_{K}\end{array}$ \\
\hline \multirow{3}{*}{$\begin{array}{l}\text { Case A } \\
(U \& S \\
\text { enemies) }\end{array}$} & $\boldsymbol{U}$ & $\downarrow$ & $\downarrow$ & $\uparrow$ \\
\hline & $s$ & $\downarrow$ & $\downarrow$ & $\uparrow$ \\
\hline & $\boldsymbol{K}$ & $\uparrow$ & $\uparrow$ & $\downarrow$ \\
\hline \multirow{3}{*}{$\begin{array}{l}\text { Case B } \\
\text { (S \& } K \\
\text { enemies) }\end{array}$} & $\boldsymbol{U}$ & $\downarrow$ & $\uparrow$ & $\uparrow$ \\
\hline & $S$ & $\bar{\uparrow}$ & 1 & $\downarrow$ \\
\hline & $\boldsymbol{K}$ & $\uparrow$ & $\downarrow$ & $\downarrow$ \\
\hline \multirow{3}{*}{$\begin{array}{l}\text { Case C } \\
\text { (U \& } K \\
\text { enemies) }\end{array}$} & $\boldsymbol{U}$ & $\downarrow$ & $\uparrow$ & $\downarrow$ \\
\hline & $s$ & $\uparrow$ & $\downarrow$ & $\uparrow$ \\
\hline & $\boldsymbol{K}$ & $\downarrow$ & $\uparrow$ & $\downarrow$ \\
\hline KEY: & $\mathrm{fa}$ & $\begin{array}{l}\text { return incr } \\
\text { return dec }\end{array}$ & & \\
\hline
\end{tabular}


Table 2

Effects on inequality in host and source countries as a result of factor migration

\begin{tabular}{|c|c|c|c|c|c|c|c|}
\hline \multirow{2}{*}{\multicolumn{3}{|c|}{ FACTOR FLOWS }} & \multicolumn{2}{|c|}{ HOST COUNTRY } & \multicolumn{3}{|c|}{ SOURCE COUNTRY } \\
\hline & & & \multirow{2}{*}{$\frac{\text { Citizens }}{\uparrow}$} & Residents & Citizens & \multicolumn{2}{|c|}{ Residents } \\
\hline \multirow{3}{*}{$\begin{array}{l}\text { Case A } \\
\text { (U \& S } \\
\text { enemies) }\end{array}$} & & $\boldsymbol{U}$ & & $\uparrow \odot$ & $\downarrow \dagger$ & $\downarrow$ & $\otimes$ \\
\hline & & $S$ & $\uparrow$ & $\uparrow$ & $\downarrow \dagger$ & $\downarrow$ & \\
\hline & & $\boldsymbol{K}$ & $\downarrow \dagger$ & $\downarrow 0$ & $\uparrow$ & $\bar{\uparrow}$ & $\otimes$ \\
\hline \multirow{3}{*}{$\begin{array}{l}\text { Case B } \\
\text { (S \& } K \\
\text { enemies) }\end{array}$} & & $U$ & $\uparrow \dagger$ & $\uparrow$ & $\downarrow$ & 1 & \\
\hline & & $S$ & 1 & $\downarrow$ & $\uparrow \dagger$ & $\uparrow$ & \\
\hline & & $K$ & $\downarrow$ & 1 & $\uparrow \dagger$ & $\bar{\uparrow}$ & \\
\hline \multirow{3}{*}{$\begin{array}{c}\text { Case C } \\
(U \& K \\
\text { enemies) }\end{array}$} & & $\bar{U}$ & $x$ & $x \otimes$ & $x+$ & $x$ & $\otimes$ \\
\hline & & $S$ & $x+$ & $x \quad 0$ & $x$ & $x$ & $\theta$ \\
\hline & $\boldsymbol{K}$ & $\mathbf{K}$ & $x$ & $x$ & $x$ & $x$ & \\
\hline KEY: & $\begin{array}{ll}\uparrow & \text { ir } \\
\downarrow & \text { ir } \\
\times & \text { L } \\
\dagger & \text { a } \\
\otimes & \text { a }\end{array}$ & $\begin{array}{l}\text { ineq } \\
\text { ineq } \\
\text { Lore } \\
\text { ambi } \\
\text { ambi }\end{array}$ & $\begin{array}{l}\text { lity increases } \\
\text { lity declines } \\
\text { curves inters } \\
\text { lous for non- } \\
\text { lous: leading }\end{array}$ & $\begin{array}{l}\text { at } \\
\text { arginal migrat } \\
\text { se indicated }\end{array}$ & flows & & \\
\hline
\end{tabular}




\section{Case A: Distribution among Citizens}

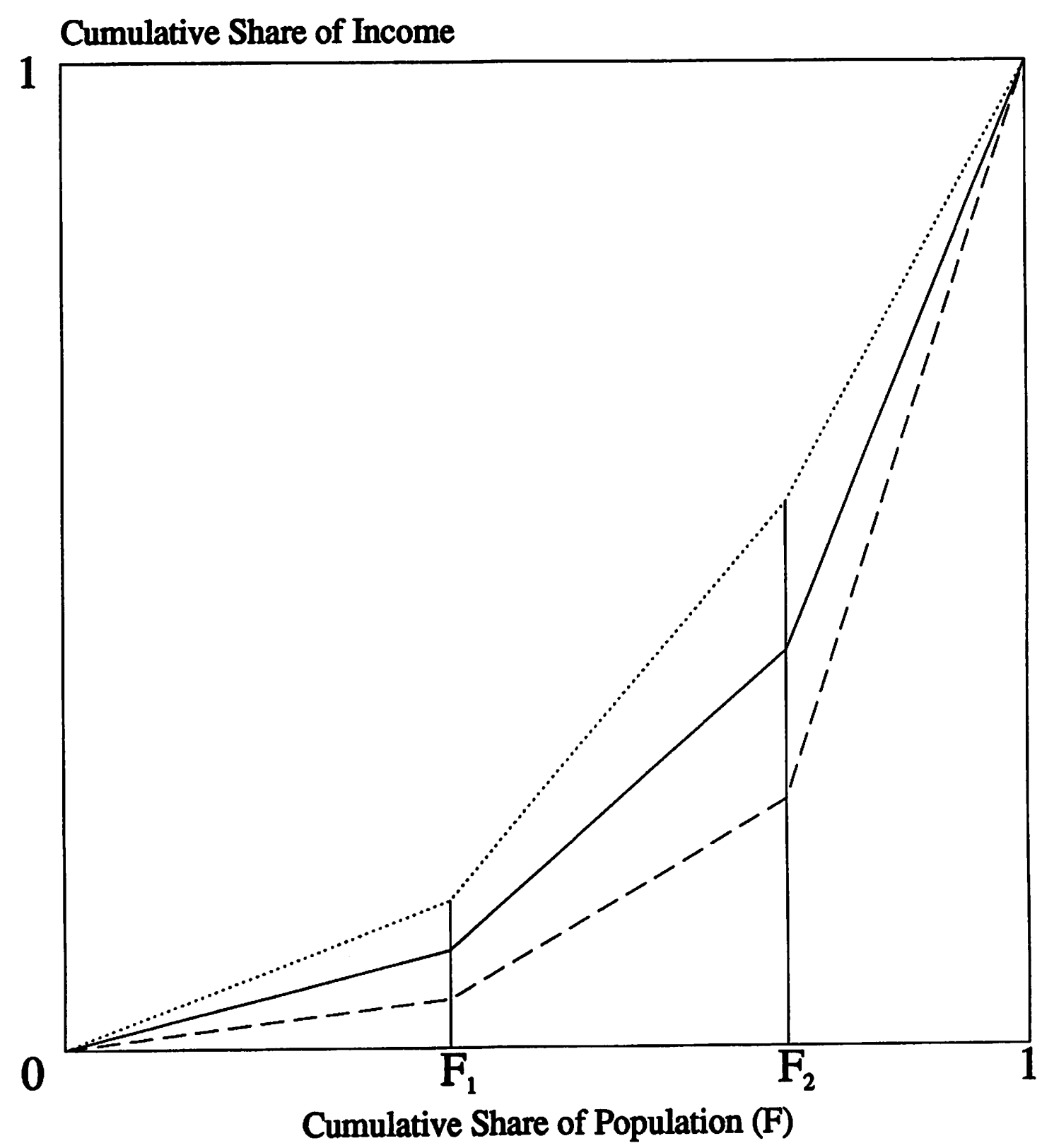

$s$

K Immigration $\quad-\cdots$ U,S Immigration 


\section{Case B: Distribution among Citizens}

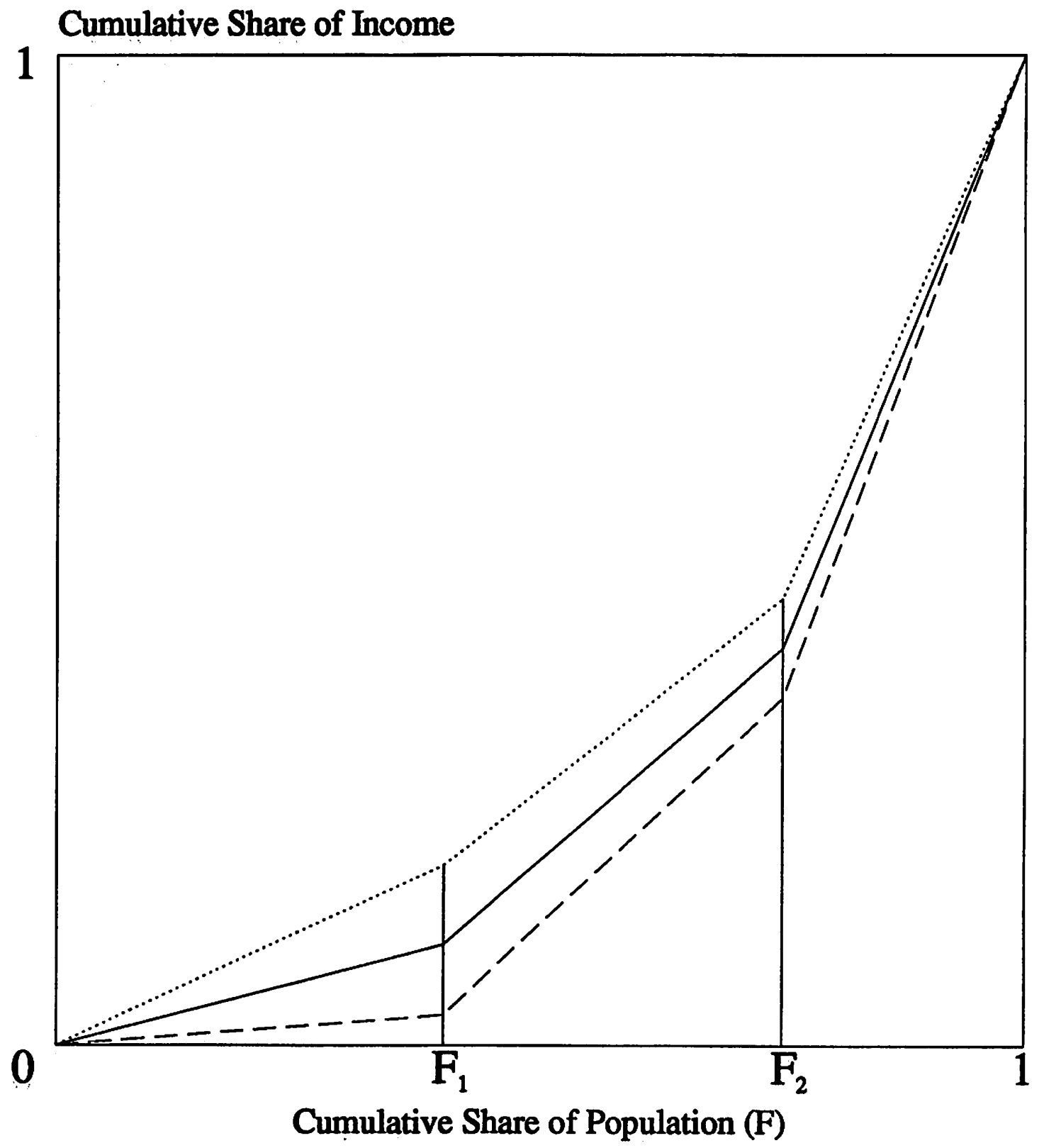

S,K Immigration $\quad--\cdot$ U Immigration

FIGURE 2 


\section{Case C: Distribution among Citizens}

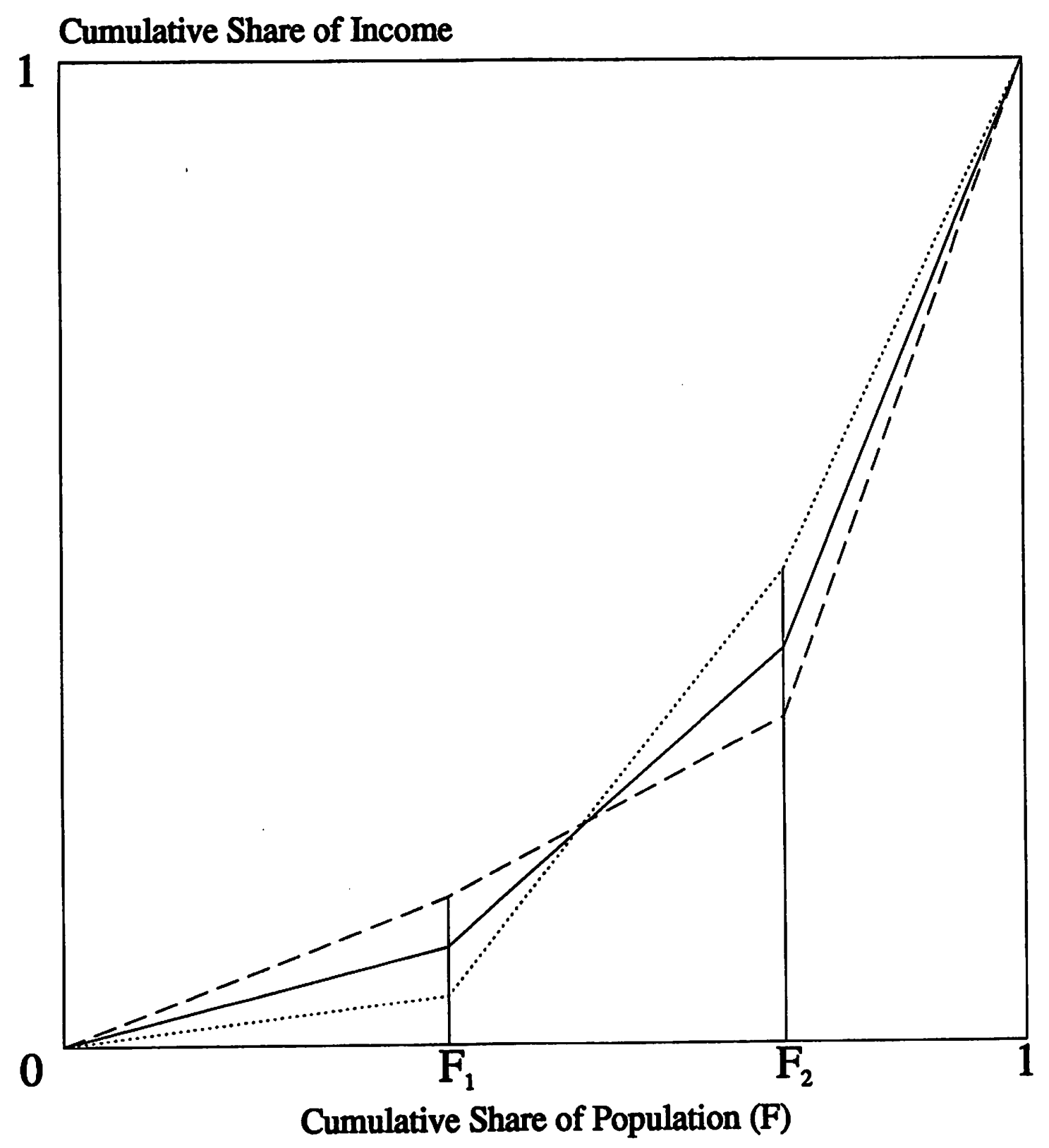

U,K Immigration $\quad-\cdots$ S Immigration

FIGURE 3 


\section{INCOME INEQUALITY AND INTERNATIONAL MIGRATION}

\section{James B. Davies and Ian Wooton}

APPENDIX

The purpose of this appendix is to prove three propositions which indicate when the ambiguity in Case A, caused by changes in $\bar{w}_{R}$ in the host and source countries due to migration of the unskilled, can be ignored. Parallel conditions can be provided to eliminate the ambiguities in other cases.

PROPOSITION 1: Under immigration by the unskilled, the Lorenz curve for residents of the host country will move down unambiguously if

$$
\varepsilon_{w_{U}}^{U}, \varepsilon_{w_{U}}^{S}>-\frac{1}{D}
$$

where $\varepsilon_{w_{U}}^{U}$ and $\varepsilon_{w_{U}}^{S}$ are the general-equilibrium elasticities of demand for $U$ and $S$ with respect to $w_{U}$ and $D$ is the proportional 'income deficit of the unskilled', $D \equiv\left(\bar{w}_{R}-w_{U}\right) U / Y$.

PROOF: We have:

$$
\bar{w}_{R}=\frac{w_{U} U+w_{S} S+w_{K} K}{U+S+K}=\frac{Y}{V}
$$

where $K$ is the number of capital owners and $V$ is the size of the total population. Now:

$$
\frac{\partial \bar{w}_{R}}{\partial U}=\frac{1}{V^{2}}\left(V \frac{\partial Y}{\partial U}-Y\right)
$$

and since by $(9),(\partial Y / \partial U)=w_{U}$ :

$$
\frac{\partial \bar{w}_{R}}{\partial U}=\frac{w_{U}}{V}-\frac{Y}{V^{2}}=\frac{w_{U}-\bar{w}_{R}}{V}
$$

since $Y=\bar{w}_{R} V$. Converting to an elasticity:

$$
D=-\left[\frac{U}{\bar{w}_{R}} \frac{\partial \bar{w}_{R}}{\partial U}\right]=\frac{\left(\bar{w}_{R}-w_{U}\right) U}{Y}
$$

Now if the elasticities of $w_{U}$ and $w_{S}$ with respect to $U$ are greater than $D$ in absolute value $w_{U} / \bar{w}_{R}$ and $w_{S} / \bar{w}_{R}$ will both decline. The inequality stated in the proposition is equivalent. 
A parallel statement holds for inequality among residents of the source country. That is,

PROPOSITION 2: Under emigration by the unskilled, the Lorenz curve for residents of the source country will move up unambiguously if:

$$
\varepsilon_{w_{U}}^{U^{*}}, \varepsilon_{w_{U}}^{S^{*}}>-\frac{1}{D^{*}}
$$

Finally, for the distribution of income among citizens of the source country we have:

PROPOSITION 3: Under emigration by the unskilled, the Lorenz curve for citizens of the source country will move up unambiguously if:

$$
\varepsilon_{w_{U}}^{U^{*}}, \varepsilon_{w_{U}}^{S^{*}}>-\frac{1}{D^{\prime}}
$$

where $D^{\prime}$ is the 'proportional income deficit' of the unskilled in the source country with respect to the wages of the unskilled in the host country, rather than being with respect to mean income in their own country, that is $D^{\prime} \equiv\left(w_{U}-w_{U}^{*}\right) U^{*} / G^{*}$.

PROOF: $\quad$ Here we have:

$$
\bar{w}_{C}^{*}=\frac{w_{U}^{*} U^{*}+w_{S}^{*} S^{*}+w_{K}^{*} K^{*}+w_{U} \hat{U}}{U^{*}+S^{*}+K^{*}+\hat{U}}=\frac{Y^{*}+w_{U} \hat{U}}{V^{*}+\hat{U}}
$$

where $\hat{U}$ gives the number of unskilled citizens of the source country who have immigrated to the host country. Noting that $\left(\partial \hat{U} / \partial U^{*}\right)=-1$,

$$
\frac{\partial \bar{w}_{C}^{*}}{\partial U^{*}}=\left[\frac{1}{V^{*}+\hat{U}}\right]\left(w_{U}^{*}-w_{U}\right)
$$

and observing that $G^{*}=\bar{w}_{C}^{*}\left(V^{*}+\hat{U}\right)$ :

$$
D^{\prime}=-\left[\frac{U^{*}}{\bar{w}_{C}^{*}} \frac{\partial \bar{w}_{C}^{*}}{\partial U^{*}}\right]=\frac{\left(w_{U}-w_{U}^{*}\right) U^{*}}{G^{*}} .
$$

If the elasticities of $w_{U}^{*}$ and $w_{S}^{*}$ with respect to $U^{*}$ are greater than $D^{\prime}$ in absolute value $w_{U}^{*} / \bar{w}_{C}^{*}$ and $w_{S}^{*} / \bar{w}_{C}^{*}$ will both increase as $U^{*}$ declines. Inverting to get demand elasticities we obtain the stated inequality. $\square$ 